\title{
UNIDADE GESTORA DO REGIME PRÓPRIO DE PREVIDÊNCIA SOCIAL: ESTUDO DE SUA IMPLEMENTAÇÃO PELOS ESTADOS BRASILEIROS
}

\author{
MANAGEMENT UNIT OF THE OWN REGIME OF SOCIAL SECURITY: \\ STUDY OF ITS IMPLEMENTATION BY THE BRAZILIAN STATES
}

Gisele de Freitas ${ }^{1}$

Thiago de Melo Teixeira da Costa ${ }^{2}$

Suely de Fátima Ramos Silveira ${ }^{3}$

1

Bacharel em Ciências Contábeis, Mestre em Administração pela Universidade Federal de Viçosa e Professora do Instituto Federal do Sul de Minas Gerais. 2

Mestre e Doutor em Economia Aplicada pela Universidade Federal de Viçosa, Bacharel em Administração, Professor Associado do Departamento de Administração e Contabilidade da Universidade Federal de Viçosa. 3

Doutora em Ciências (Economia Aplicada) pela ESALq / Universidade de São Paulo, Professora do Programa de PósGraduação da Universidade Federal de Viçosa (UFV).

Diretora do Instituto de Políticas Públicas e Desenvolvimento Sustentável - IPPDS da UFV, Brasil.
Resumo: Considerada parte da política pública de equilíbrio financeiro e atuarial da Previdência Social, a Unidade Gestora é objeto da presente pesquisa que analisa seu processo de implementação pelos estados brasileiros. Este trabalho foi motivado pelo fato da unidade gestora possuir a EC 41/2003 como seu marco legal, contudo, na prática estudos comprovam a inexistência da unidade gestora em maior parte dos estados brasileiros. Para a produção dos resultados utilizou-se a bibliografia sobre implementação de políticas públicas para traçar categorias que serviram de base às analises de atas, legislações e questionários, que foram os dados coletados por essa pesquisa. As análises ocorreram pela técnica de análise de conteúdo e permitiram concluir que a divergência de informações, conflitos de interesses, falta de definição de recursos em tempo hábil e não especificação de processo de supervisão são os principais elementos para não existência da unidade gestora efetivas em todos os estados brasileiros.

PALAVRAS CHAVE: unidade gestora; implementação; RPPS.

ABSTRACT: Considered part of the public policy of financial and actuarial balance of Social Security, the Management Unit is the object of the present research that analyzes its implementation process by the Brazilian states. This work was motivated by the fact that the management unit has EC 41/2003 as its legal framework, however, in practice studies prove its lack in most of the Brazilian states. For the production of the results, the bibliography on the implementation of public policies was used to draw categories that served as a basis for the analysis of minutes, legislations and questionnaires, which were the data collected by this research. The analysis took place through the technique of content analysis and allowed to conclude that the divergence of information, conflicts of interest, lack of definition of resources in a timely manner and not specification of supervision process are the main elements for the non existence of the effective

KEYWORDS: unit management; implementation; RPPS. 


\section{INTRODUÇÃO}

Ao refletir sobre o processo de reforma da Previdência Social no Brasil, destacam-se as instituídas com a publicação da Emenda Constitucional 20/1998 e da Emenda Constitucional 41/2003, onde é possível perceber a presença de mecanismos para tentar resolver o polêmico problema do desequilíbrio financeiro e atuarial da Previdência Social no país.

Ao tomar este problema como fato, Nogueira (2012) destaca que a busca pelo equilíbrio financeiro e atuarial é um dos princípios fundamentais de estruturação e organização do Regime Próprio de Previdência Social- RPPS. Dessa forma, segundo o autor, mais que um princípio constitucional, a busca pelo equilíbrio financeiro e atuarial pode ser considerada uma política pública, cujas principais áreas de atuação são: o equacionamento do déficit atuarial passado, a regularidade no repasse das contribuições, a política de investimentos e a gestão dos benefícios.

Neste contexto, a EC 41/2003 apresenta a vedação da existência de mais de um RPPS e de mais de uma unidade gestora do respectivo regime em cada ente federativo, criando a unidade gestora única.

A unidade gestora é uma entidade ou um órgão de cada ente federativo responsável por todas as atividades do RPPS. Se anteriormente existia uma gestão de RPPS para o Poder Judiciário, uma para o Legislativo e uma para o Executivo, com a unidade gestora passa a existir uma única gestão para todos os Poderes com a função de agregar os benefícios de, no mínimo, aposentadoria e pensão, além de outros deveres e obrigações instituídos pelos instrumentos legais.

Contudo, a nível estadual, Calazans e colaboradores (2012) apontam em seus estudos que, apenas Minas Gerais, Espírito Santo e Tocantins possuem unidades gestoras efetivas, pois nem todos os elementos que as compõe a legislação referente a unidade gestora são encontrados na prática da forma como estão previstos em lei. Ou seja, apenas os três estados apresentados possuiriam a unificação das atividades de gestão do RPPS em um único órgão denominado unidade gestora.

Diante do exposto, é notável a lacuna existente entre legislação e prática, surgindo a seguinte questão de pesquisa: Como ocorreu o processo de implementação a unidade gestora, que possui a EC 41/2003 como seu marco legal, mas cujo resultado não expressa a existência de unidades gestoras efetivas?

Segundo Secchi (2013) as políticas públicas podem ser estudadas através de seis etapas ou fases: identificação do problema; formação da agenda; formulação de alternativas; tomada de decisão; implementação; avaliação e extinção. Assim, o objetivo geral deste artigo é verificar o processo de implementação da unidade gestora do Regime Próprio de Previdência Social nos estados brasileiros, a fim de compreender os motivos para não existência de unidade gestoras efetivas em todos eles. 


\section{UNIDADE GESTORA DE REGIMES PRÓPRIOS DE PREVIDÊNCIA SOCIAL}

A EC 41/2003 institui no parágrafo 20 do artigo 40, que "Fica vedada a existência de mais de um regime próprio de previdência social para os servidores titulares de cargos efetivos, e de mais de uma unidade gestora do respectivo regime em cada ente estatal [...]". Contudo, não detalha sobre como a legislação deverá ser cumprido na prática.

Assim, apesar de exigida pela EC 41/2003, a unidade gestora única de RPPS passou por um processo de definição e formas de operacionalização, em que diversos instrumentos normativos foram criados. O primeiro deles é a Lei 10.887 de 18 de junho de 2004 que trata da aplicação da EC 41/2003. Nesta lei fica estabelecida que a unidade gestora do Regime Próprio de Previdência deverá contar com colegiado de participação paritária de representantes e de servidores dos Poderes da União, cabendo-lhes acompanhar e fiscalizar sua administração, na forma do regulamento. Além disso, a unidade gestora deverá disponibilizar ao público, inclusive por meio de rede pública de transmissão de dados, informações atualizadas sobre as receitas e despesas do respectivo regime, bem como os critérios e parâmetros adotados para garantir o seu equilíbrio financeiro e atuarial.

Posteriormente, foi emitida pelo Ministério da Previdência Social e Secretaria de Políticas de Previdência Social a Orientação Normativa no 03 de 12 de agosto de 2004 que trouxe a definição de unidade gestora de RPPS como: entidade ou órgão integrante da estrutura da administração pública de cada ente federativo, cuja finalidade seja a administração, o gerenciamento e operacionalização do RPPS, em que estão incluídas as atividades de arrecadação e gestão de recursos e fundos previdenciários, a concessão, o pagamento e a manutenção dos benefícios. Além disso, essa orientação acrescenta à Lei 10.887 que a unidade gestora deve estar vinculada ao Poder Executivo. Destaca que a unidade gestora deverá centralizar, no mínimo a concessão, o pagamento e manutenção dos benefícios de aposentadoria e pensão e deverá dar acesso livre ao Auditor Fiscal da Previdência Social para a inspeção de livros, notas e demais documentos necessários ao perfeito desempenho das funções de uma unidade gestora.

Posteriormente, ocorreu a emissão da Portaria 402 de 10 de dezembro de 2008 pelo Ministério da Previdência Social e Secretaria de Políticas de Previdência Social, reforça o conceito de unidade gestora e suas funções, acrescentando que ela poderá gerenciar direta ou indiretamente a concessão, o pagamento e a manutenção, de no mínimo, aposentadoria e pensão concedidas a partir da publicação da Emenda Constitucional 41/2003, de todos os poderes, órgãos e entidades do ente federativo. Reafirma o acesso dos segurados às informações e o livre acesso do Auditor Fiscal da Receita Federal do Brasil à unidade gestora de RPPS. 
Em 31 de março de 2009 foi emitida uma nova Orientação Normativa pelo Ministério da Previdência Social e Secretaria de

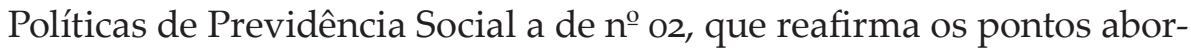
dados pelos instrumentos anteriores e acrescenta a definição dos recursos para se atingir o objetivo de implementação da unidade gestora. Assim, para cumprir este papel, a orientação normativa preconiza que para a cobertura das despesas do RPPS com utilização dos recursos previdenciários poderá ser estabelecida, em lei, uma taxa de administração de até $2 \%$ do valor total das remunerações, proventos e pensões dos segurados vinculados ao RPPS, relativos ao exercício financeiro anterior, que deverá ser utilizada exclusivamente para o custeio das despesas correntes e de capital necessárias a organização e ao funcionamento da unidade gestora de RPPS, inclusive para a conservação de seu patrimônio.

Ao analisar estes instrumentos, fica claro a expectativa de que com a implementação da unidade gestora pelos entes federativos espera-se a diminuição das sobreposições de funções, redução dos custos para o sistema, racionalização para melhor operacionalização das atividades, diminuição da descentralização administrativa para acesso a maior volume de informações e informações mais confiáveis, refletindo no ajuste do desequilíbrio financeiro e atuarial (CALAZANS et al., 2013).

Contudo, Calazans e Caetano (2013) mostram que na prática a unidade gestora de fato não existe para a maior parte dos estados brasileiros.

A unidade gestora é uma entidade ou órgão da administração pública que é responsável pela administração, o gerenciamento e operacionalização do RPPS, incluindo todas as atividades pertinentes ao regime, ou seja, arrecadação e gestão dos recursos e fundos, concessão, pagamento e manutenção dos benefícios de, no mínimo, aposentadoria e pensão, de todos os poderes, órgãos e entidades de cada ente federativo.

Segundo Calazans e Caetano (2013) no ano de 2011 existiam 1 RPPS distrital, 26 estaduais, 2.272 municipais, totalizando 2.299 RPPS no Brasil. Contudo, o estudo de Calazans et al. (2013) conclui que, se tratando do nível estadual, apenas Minas Gerais, Tocantins e Espírito Santo possuem unidades gestoras exercendo todas as suas funções conforme previsto na legislação. Assim, apesar de previsto em lei, não se pode afirmar que todo RPPS possui unidade gestora única e efetiva, ou seja, realizando todas as funções que lhes são destinadas.

\section{IMPLEMENTAÇÃO DE POLÍTICAS PÚBLICAS}

Baseado no primeiro trabalho de modelação das políticas públicas proposto por Harold D. Lasswel (1902-1978), Secchi (2013) relata que as políticas públicas podem ser estudadas através de seis etapas ou fases que são: identificação do problema; formação da agenda; formulação de alternativas; tomada de decisão; implementação; avaliação 
e extinção. Essas etapas não necessariamente ocorrem de maneira seqüencial. Contudo, cada uma delas deve ser conhecida com detalhes para que a política possa ser avaliada adequadamente.

Segundo Frey (2015), as etapas auxiliam na análise processual, uma vez que são atribuídas funções específicas a cada estágio da política, em que se pode obter comparações entre o real com um tipo puro, fornecendo elementos sobre as possíveis causas dos déficits do processo na solução do problema.

No que se refere ao termo implementação, Brynard e De Coning (2006) apresentam duas definições: como substantivo, é o estado de ter alcançado os objetivos da política; como verbo, é o processo na tentativa de alcançar o objetivo. $\mathrm{O}$ autor destaca que não é porque a implementação (substantivo) não é alcançada que a implementação (verbo) não aconteça. Assim, faz sentido o exposto por Jann e Wegrich (2007) que dizem que as políticas e suas intenções muito frequentemente são alteradas até mesmo distorcidas e sua execução pode ficar atrasada ou mesmo totalmente bloqueada.

Mesmo não existindo uma teoria formal sobre o processo de implementação, alguns estudiosos sobre o assunto levatam diversos elementos que seriam fundamentais para a compreensão desse processo. Dentre eles, Jann e Wegrich (2007, p.52) defendem que o processo de implementação ideal possuíria os seguintes elementos:

Especificação de detalhes do programa: como e por que as agências ou organizações devem executar. E como a lei ou programa deve ser interpretado. Alocação de recursos: como são distribuídos os orçamentos. Que pessoal irá executar. Quais as unidades de uma organização será responsável pela execução. Decisões: como é que as decisões de casos isolados são realizadas.

Convergindo com essas idéias, Rein e Rabinovitz (1993) afirmam que a implementação ocorre em três fases principais. A primeira seria o desenvolvimento de diretrizes, em que estas são desenvolvidos no momento em que a intenção legislativa é traduzido em requisitos administrativos para a ação. Posteriormente são promulgadas para os membros dos departamentos. No caso da legislação federal, as novas regulamentações e diretrizes são publicadas no Jornal Oficial e muitas vezes passam por mudanças após as partes terem tido a oportunidade de questioná-los. A segunda se refere a distribuição de recursos, que acontece entre as entidades administrativas responsáveis pela aplicação da legislação. No entanto, o montante total de recursos disponíveis pode, em alguns casos, não ser determinado com antecedência, uma vez que geralmente surgem discrepâncias entre o que é cedido com o autorizado. Além disso, o momento preciso em que os recursos estão disponíveis, também é crucial para a implementação. E a terceira seria a supervisão, em que existe a necessidade de algum processo de monitoramento como um mecanismo para promover a responsabilidade nos níveis inferiores no processo de implementação. 
Rein e Rabinovitz (1993) ainda defendem a existência de três imperativos que regem a implementação e estão presentes nas três fases anteriormente expostas: o imperativo legal, defendendo a obrigação legal de cumprir o requisito legislativo, ou seja, a lei em si torna-se o ponto de referência para todas as partes interessadas no processo; o imperativo burocrático-racional que corresponde ao processo pelo qual o executivo e a burocracia estão empenhados em resolver os problemas, onde os critérios para uma solução aceitável inclui o que, do ponto de vista burocrático, é um curso correto de ação moralmente, administrativamente viável e intelectualmente defensável; e o imperativo consensual que tem como preocupação central o acordo entre as posições conflitantes suportados pelos principais jogadores - o legislativo, executivo e agência administrativa, juntamente com seus respectivos círculos eleitorais.

Esses autores também destacam que condições ambientais são importantes no processo de implementação, sendo as principais: a importância dos objetivos, a complexidade do processo e a natureza e volume de recursos disponíveis. A importância dos objetivos está relacionada com a clareza da legislação com relação à suas finalidades, se o que se espera é o cumprimento imediato dos objetivos ou se ocorre apenas um processo simbólico, além da urgência na implementação em comparado com os outros objetivos que persegue. Já a complexidade do processo, dependerá do número de níveis, instâncias, partes envolvidas no processo ou no poder de veto em qualquer parte do processo e a qualquer tempo. Por fim, a implementação também é determinada pela natureza e o volume de recursos.

Assim,

Em conclusão, podemos afirmar que a implementação da política é regida, por pelo menos, três imperativos formais: 1) o respeito à intenção legal (ou seja, a racionalidade jurídica), que 2) é mediada pelo interesse na racionalidade instrumental, como definido por funcionários públicos e, por sua vez, este tipo de racionalidade 3) é guiado pelo reconhecimento de que a ação interna e externa exige consenso. A melhor maneira de compreender a implementação de políticas é considerando como uma tentativa de resolver o conflito entre esses imperativos. A maneira pela qual esses conflitos são resolvidos depende dos fins (clareza, proeminência e consistência), os recursos (tipo, nível e tempo) e à complexidade do processo administrativo da implementação (REIN E RABINOVITZ, 1993 p. 184 - tradução nossa). 


\section{PROCEDIMENTOS METODOLÓGICOS}

Para cumprir o objetivo deste artigo foi utilizada a pesquisa documental. Foram analisadas as legislações federais e estaduais que tratam sobre a unidade gestora. A nível estadual foram analisadas 23 leis, uma vez que não foi possível identificar a legislação dos estados do Ceará, Maranhão, Piauí e Roraima.

Além disso, foram analisadas 51 atas do Conselho Nacional dos Dirigentes de Regimes Próprios de Previdência Social - Conaprev, do ano de 2001 ao ano de 2014. Essas atas estão disponíveis no site do Ministério da Previdência Social e possuem livre acesso.

Também foram utilizados dados primários, com aplicação de questionários aos dirigentes de Regime Próprio de Previdência Social dos estados brasileiros, a fim de extrair informações sobre a realidade da unidade gestora. Foi possível contar com apoio do Conaprev, que informou aos dirigentes sobre o conteúdo da pesquisa e enviou os questionários para 27, via correio eletrônico. Ligações foram efetivadas pelos pesquisadores deste artigo aos dirigentes, no sentido obter maior número de respostas. Mesmo com todo esforço dispendido, houve o retorno de apenas 9 questionários que foram analisados com intuito de complementar os resultados encontrados pelos demais instrumentos da pesquisa.

Os dados coletados foram tratados por meio da análise de conteúdo. As categorias e subcategorias foram definidas através do referencial teórico sobre implementação (Quadro 1).

Vale destacar que, a delimitação dessa pesquisa a nível estadual se dá por ser uma das maiores fontes de déficit do sistema previdenciário, possuir estudos anteriores como o de Calazans et. al (2013), Velten (2013), Cavalcante Júnior e Almeida (2012), Santos (2014) que permitam uma condição mais sólida para análises e por possuir significado para posterior condução ao nível municipal e federal, dando abertura a pesquisas futuras. 
QUADRO 1: Categorias de análise da implementação da unidade gestora.

\begin{tabular}{|l|l|l|l|}
\hline Categorias & Imperativo Legal & $\begin{array}{l}\text { Imperativo Racional - } \\
\text { Burocrático }\end{array}$ & Imperativo Consensual \\
\hline $\begin{array}{l}\text { Elaboração das } \\
\text { diretrizes }\end{array}$ & $\begin{array}{l}\text { Requisitos legislativos: como } \\
\text { a lei deve ser interpretada; } \\
\text { como deve ser executada; } \\
\text { por que deve ser executada. } \\
\text { Ou seja, a lei serve como } \\
\text { ponto de referência para a } \\
\text { implementação? }\end{array}$ & $\begin{array}{l}\text { Decisões dos } \\
\text { implementadores: } \\
\text { questionamentos à lei; } \\
\text { decisões em casos isolados. }\end{array}$ & $\begin{array}{l}\text { Atores envolvidos no } \\
\text { processo e acordo entre as } \\
\text { posições conflitantes. }\end{array}$ \\
\hline Definição dos Recursos & $\begin{array}{l}\text { Como são definidos os } \\
\text { recursos pela legislação. }\end{array}$ & $\begin{array}{l}\text { Como são definidos os } \\
\text { recursos no momento da } \\
\text { implementação. }\end{array}$ & $\begin{array}{l}\text { Conflito entre os atores } \\
\text { envolvidos no que se } \\
\text { refere aos recursos. }\end{array}$ \\
\hline Supervisão & $\begin{array}{l}\text { Definição legal de } \\
\text { monitoramento, inspeção ou } \\
\text { avaliação. }\end{array}$ & $\begin{array}{l}\text { Monitoramento, inspeção } \\
\text { e avaliação definida } \\
\text { e praticada pelos } \\
\text { implementadores. }\end{array}$ & $\begin{array}{l}\text { Conflito entre os atores } \\
\text { envolvidos no que se } \\
\text { refere à supervisão. }\end{array}$ \\
\hline
\end{tabular}

FONTE: Autores da Pesquisa.

\section{RESULTADOS E DISCUSSÕES}

\section{ELABORAÇÃO DAS DIRETRIZES SOBRE UNIDADE GESTORA}

Conforme exposto no referencial teórico deste artigo, a legislação que institui a unidade gestora única de RPPS é a Emenda Constitucional $\mathrm{n}^{\mathrm{o}} 41$ de 19 de dezembro de 2003. Contudo, outros instrumentos legais surgiram para tentar esclarecer pontos específicos sobre unidade gestora: a Lei n⿳ํㅜ10.887 de 18 de junho de 2004, a Orientação Normativa nº3 de agosto de 2004, a Portaria nº̣02 de dezembro de 2008 e Orientação Normativa no02 de março de 2009.

De acordo com o imperativo legal, no âmbito da elaboração das diretrizes, identificar como a lei deve ser interpretada, como é executada e porque executá-la são elementos de fundamental importância para compreender o processo de implementação. 
$\mathrm{Na}$ ata da $12^{\underline{a}}$ reunião ordinária do Conaprev, realizada em 24 de junho de 2004, foi discutido pelos representantes de RPPS dos estados brasileiros e do Ministério da Previdência a necessidade de uma definição mais clara sobre unidade gestora, já que a existente na EC 41/2003 e na Lei 10.887/2004 não eram suficientes. O representante do Ministério da Previdência Social - MPS tentou esclarecer os pontos de dúvida sobre unidade gestora, relatando que o órgão deveria unificar todas as atividades pertinentes à Previdência Social. Contudo, nenhum detalhe foi apresentado sobre como fazer a legislação se tornar realidade.

Além disso, no que se refere à organização formal da unidade gestora, fica claro na ata que os estados acreditavam que deveriam criar uma autarquia ou fundo, como previa a legislação, mas o representante do MPS esclareceu que os departamentos já existentes dentro das secretarias poderiam assumir este papel, não sendo necessária a criação de um outro órgão.

Seis anos após os esclarecimentos, na $32^{2}$ reunião do Conaprev em 2010, p. 5, os representantes de RPPS dos estados continuavam com dúvidas sobre a formalização da unidade gestoras, embasados na legislação vigente, e o representante do MPS reforçou que "a unidade gestora de RPPS é integrante do ente federativo, não sendo uma unidade autônoma". Isso demonstrava que a lei seguia em uma direção e os esclarecimentos prestados pelo MPS não convergiam, gerando conflito de interpretação entre os executores da política.

Retornando à ata da $12^{\underline{a}}$ reunião, o assunto referente ao acesso às informações sobre a gestão dos RPPS foi abordado. A dúvida estava pautava sobre se esse acesso deveria ocorrer a qualquer pessoa, se tornando público os demonstrativos contábeis financeiros previdenciários e demais dados, conforme preconizava o texto que daria origem a Orientação Normativa 03/2004. O representante do MPS, explicou que o acesso à informação deveria ser dado apenas ao segurado que fizesse o requerimento, ou seja, apenas o segurado tem direito a esse acesso e não qualquer cidadão. Contudo a Orientação Normativa 03 de agosto de 2004, foi publicada relatando que o acesso à informação deveria ser prestado ao público pela rede pública de transmissão de dados, sem fazer nenhuma distinção. Apenas com Portaria n⿳002/2008 é que ocorreu a restrição do acesso à informação ao segurado, ou seja, de 2003 a 2008 os executores da política não sabiam exatamente como proceder.

Corroborando com os aspectos discutidos até o momento, na análise dos questionários os respondentes relatam sobre alguns dos instrumentos que colocam a unidade gestora legalmente exigível e que a definiu, como a EC 41/2003, a Portaria 402/2008 e a Orientação Normativa 02/2009.

Sobre a clareza desses instrumentos, os respondentes disseram que são claros, existindo uma definição dos objetivos que se queria atingir com a implementação da unidade gestora. Todos os respondentes concordam que a ON 02/2009, ou seja, cinco anos depois da EC 41/2003, define como a unidade gestora deve ser implementada, contu- 
do, Amazonas, Minas Gerais e São Paulo não acreditam que essa informação seja executável. O dirigente de RPPS do estado de Tocantins acrescentou que a reforma da previdência social foi uma iniciativa do governo federal e que coube ao Estado adequar sua legislação às novas regras impostas pela Constituição Federal.

Quando questionados sobre a importância da implementação da unidade gestora para a consecução do equilíbrio financeiro e atuarial, com exceção de Minas Gerais, os demais dirigentes acreditam ser importante, com destaques para os seguintes elementos: pela padronização na aplicabilidade da legislação previdenciária na concessão, manutenção e pagamento dos benefícios previdenciários bem como pela gestão dos recursos previdenciários, mais precisamente dos recursos dos fundos previdenciários capitalizados, que exigem um corpo técnico experiente e qualificado na sua gestão para ter o equilíbrio financeiro e atuarial dos planos previdenciários ao longo do tempo e para pagamento dos atuais e futuros benefícios; otimização de esforços, critérios uniformes para benefícios, maximização de resultados; a concentração da gestão do RPPS em apenas um órgão, com a participação dos demais interessados por meio dos Conselhos de Administração e Fiscal, corroboração para uma administração mais ágil, eficaz e econômica; segregação de responsabilidades com a previdência e possibilita ao Estado canalizar recursos para áreas prioritárias.

Dessa forma, foi possível identificar que os representantes dos 9 estados que responderam o questionário mostraram saber os motivos pelos quais deveriam implementar a unidade gestora, contudo, a legislação federal continuava sendo insuficiente por não evidenciar como deveria ser executada a implementação da unidade gestora.

Assim, ao analisar o processo de implementação sob a ótica do imperativo racional-burocrático é possível verificar existência de delegação legal para os executores da implementação da unidade gestora de legislar sobre o assunto, adaptando a realidade local aos preceitos federais, ou seja, existia decisões que eram tomadas isoladamente pelos atores implementadores, no caso, os dirigentes de RPPS dos estados brasileiros.

Os representantes de RPPS dos estados do Amazonas, Espírito Santo, Pará, Paraíba, Paraná, Pernambuco e Rondônia tiveram a legislação que rege o Regime Próprio de Previdência Social antes que a primeira orientação normativa que esclarecesse sobre unidade gestora fosse publicada. Esses estados, portanto, tiveram suas legislações alteradas posteriormente, na tentativa de se adequar às orientações que surgiram sobre o assunto. Dentre esses estados, apenas o do Amazonas, Espírito Santo e Paraná denominaram o órgão gestor de unidade gestora de RPPS.

Estados como Amapá e Sergipe não trazem a denominação unidade gestora em sua legislação. Contudo, ao analisar detalhadamente a legislação de Sergipe, essa possui todas as características necessárias para ser uma unidade gestora, assim como, Espírito Santo, Goiás e São Paulo. 
Estados como Acre, Mato Grosso do Sul, Rio Grande do Norte e Santa Catarina, deixam nítido em suas legislações que os Poderes e alguns órgãos devem fornecer informações à unidade gestora sobre valores de contribuição, benefícios pagos, demonstrativos individualizados, mostrando que apesar de receberem a denominação unidade gestora, não existe um único órgão exercendo todas as atividades.

Além disso, todas as unidades gestoras analisadas são entes integrantes da estrutura da administração pública do estado, em que 17 se constituíram na forma de Autarquia, 3 na forma de Serviço Social Autônomo, I Fundação e 2 em que não fica clara o tipo de entidade ou órgão formado. Dentre essas entidades, 16 foram criadas e 7 já existiam e foram reestruturadas para atender a EC 41/2003, segundo as legislações de cada estado.

Pelas atas das reuniões do Conaprev, estados como Amazonas, Ceará, Pernambuco, Mato Grosso, Mato Grosso do Sul, Minas Gerais, Rio Grande do Norte, Rio Grande do Sul, Rio de Janeiro e São Paulo apresentaram nitidamente a falta de um único órgão executando todas as atividades relativas ao RPPS. O único estado de sucesso apresentado nessa reunião foi o de Tocantins, que em 2004 o IGEPREV-TOCANTINS passou a gerir os benefícios previdenciários dos servidores públicos dos Poderes Executivo, Legislativo e Judiciário, bem como do Ministério Público, do Tribunal de Contas e dos Militares, como fica claro na ata da $2 \mathrm{O}^{\mathrm{a}}$ reunião do Conaprev ocorrida em 2006. Isso pode estar atrelado ao tamanho do estado e consequentemente a força desses poderes. Acredita-se que a influência de cada poder dentro do estado, pode ser indicativo determinante para a ocorrência ou não de conflitos de interesse e implementação da unidade gestora.

$\mathrm{Na} 22^{2}$ reunião do Conaprev em 2007 ao serem questionados sobre como ocorreu o processo de unificação de concessão, pagamento e manutenção de aposentadoria e pensão os estados apontaram as dificuldades encontradas. O dirigente do Mato Grosso do Sul afirma que é um processo que ocorre de forma gradativa. Como exemplo do que ocorreu em Minas Gerais, pode ser um processo ascendente e descente, pois possuíam a unificação, contudo, a instituição que havia sido criado em 2002 foi extinta ao final de 2013 e o processo de unificação de concessão e manutenção de benefícios interrompidos.

De acordo com o questionário, ao responderem sobre a coerência entre a legislação da unidade gestora e o que é possível de ser executado na prática no processo de implementação, os respondentes declaram que existe coerência, contudo é um processo complexo, pois as normas não detalham o processo de implementação de uma unidade gestora, a legislação apenas detalha alguns processos relacionados às atividades de uma unidade gestora, mesmo assim, alguns pontos ainda não estão claros, como a gestão previdenciária direta e indireta. Assim, o exemplo de como foi o processo de implementação em outros estados é fonte de referência para a implementação da unidade gestora. O estado de Amazonas, por exemplo, utilizou o estado do Paraná como modelo. 
Apenas os estados do Amazonas, Mato Grosso do Sul, São Paulo e Tocantins definiram etapas de implementação da unidade gestora de forma sequencial e ordenada. Contudo, somente os estados de São Paulo e Tocantins estabeleceram prazos para o funcionamento da unidade gestora nos termos da lei, de 2 anos e 5 anos, respectivamente.

Outro ponto destacado é a necessidade de criação da cultura previdenciária, pois muitas vezes reserva às unidades previdenciárias papel menos relevante em relação a outras unidades administrativas de governo, sendo uma dificuldade para a criação efetiva de uma unidade para atuar nos três poderes.

Assim, o processo de união de todos os Poderes, órgãos e entidades em uma única gestão foi complexo e em resposta ao questionário os representantes afirmam que essa complexidade reside na dificuldade de adesão de todos os poderes e unificação das peculiaridades dos Militares, além da dimensão do estado, como já apontava o estudo de Calazans e Caetano (2013) e o número de segurados.

Dessa forma, ao se analisar o imperativo consensual, um primeiro ponto de destaque é que os próprios dirigentes estaduais não estavam satisfeitos com relação às normas e isso fica claro no seguinte trecho

Eu só entendo que o Ministério não pode ficar ao 'som da maré baixa', ou enche, ou (...), impõe uma norma para a gente. A gente então, regulamenta a nossa legislação em função dessa orientação. Amanhã por interesse de não sei, qual interesse, ou qual interpretação, muda a orientação normativa, nós temos que adaptar a nossa legislação a esse novo interesse (ATA DA $12^{\underline{a}}$ REUNIÃO DO CONAPREV, 2004, 4p. 100).

Além disso, nesta mesma ata o representante de RPPS do estado do Mato Grosso do Sul, em sua fala, deixa clara a dificuldade enfrentada com relação ao apoio entre os poderes dos estados, em que os poderes entraram com uma ação direta de inconstitucionalidade da unidade gestora, alegando que os poderes, constitucionalmente, devem ser independentes. Outros estados confirmam essa afirmativa relatando sua vivência com essa mesma dificuldade, parecendo haver um consenso entre eles, exceto Ceará, Paraná, Sergipe e Tocantins, que afirmam não terem apresentado essa dificuldade.

Pelo questionário fica claro que os principais pontos de conflito para união da gestão do RPPS para todos os Poderes e Órgãos/ Entidades, segundo o estado do Amazonas, residem em alguns aspectos basilares como: cultura previdenciária ultrapassada; divergência na interpretação e aplicação da legislação previdenciária pelos Poderes; suposta perda de autonomia na gestão previdenciária levando-se em consideração o princípio da Separação dos Poderes; receio da ingerência do Poder Executivo na poupança previdenciária dos outros Poderes.

Convergindo com essa idéia, Minas Gerais assume que a autonomia constitucional dos Poderes, a pulverização centenária do processa- 
mento de benefícios de aposentadoria e o enorme volume de segurados no RPPS estadual, da ordem de meio milhão de segurados são barreiras a serem superadas.

Para representante do Rio Grande do Sul os conflitos enfrentados e ainda não resolvidos, são advindos principalmente da alegação de alguns integrantes do ente federativo da retirada da sua autonomia financeira e administrativa previstas em Lei. Ao mesmo tempo enxergam a unidade gestora sem estrutura para fazer frente às atribuições legais impostas, provocada principalmente pela inércia do poder executivo em estruturar a instituição adequadamente com recursos humanos necessários, dado o desconhecimento de alguns gestores que tomam posse a frente de algumas diretorias a cada mudança de governo.

Além disso, o próprio Ministério da Previdência Social delega responsabilidades que não convergem com o fortalecimento da unidade gestora, como é observado na $26^{\mathrm{a}}$ reunião realizada em 2008 . Ao falar do Programa de Reforma dos Sistemas Estaduais de Previdência PARSEP II o representante do ministério, relata que o poder Judiciário e Legislativo deveriam fazer seus próprios recadastramentos de dados. Contudo, isso foi questionado pelo representante de RPPS do estado de São Paulo no sentido de que, nos estados possuem unidade gestora e esse recadastramento deveria ser feito através dela, mostrando a funcionalidade desse órgão. Nesse sentido, o estado de Roraima expôs que solicitou ao governo do estado que o Instituto de Previdência fosse o responsável pela condução do recadastramento. Contudo, na 28 a reunião do Conaprev, realizada em 2009, o assunto recadastramento ressurgiu e foi esclarecido que as bases de dados devem ser colocadas em cada Poder e também no órgão gestor, demonstrando a fraqueza da unidade gestora.

Na $22^{a}$ reunião do Conaprev em 2007 algumas sugestões foram apresentadas pelos estados para a implementação da unidade gestora, dente elas a necessidade de existir mais artigos na Constituição que assegurem o desempenho das atividades das unidades gestoras e que o discurso fosse mudado para que os Poderes façam a adesão ao sistema.

Em 2005, na ata da $17^{a}$ reunião do Conaprev o caso do estado da Paraíba foi apresentado. O grande problema desse estado era com o poder Judiciário, quando dos Desembargadores começaram a se aposentar e contestar na justiça a unidade gestora.

Ainda nesta reunião foi discutida a questão dos Militares, em que o representante do estado de Minas Gerais reforça a coesão e corporativismo deste segmento. $\mathrm{O}$ vice-presidente da reunião do Conaprev em seu discurso relata que os militares são um grupo organizado, competente e eficiente e uma corporação forte, mas acredita deverá ser encontrado um consenso e propõe a formação de um texto do CONAPREV como referência, em que cada Estado trabalharia tendo em vista a sua realidade. Ao mesmo tempo sugeriu que, internamente, que se procurasse definir o que é inegociável e o que é passível de negociação com os Militares. 


\section{DEFINIÇÃO DOS RECURSOS PARA A IMPLEMENTAÇÃO DA UNIDADE GESTORA}

A legislação federal que regulamenta a unidade gestora diz que a taxa de administração deverá ser de até $2 \%$ do valor total das remunerações, proventos e pensões dos segurados vinculados ao RPPS, relativos ao exercício financeiro anterior, que deverá ser utilizada exclusivamente para o custeio das despesas correntes e de capital necessárias à organização e ao funcionamento da unidade gestora de RPPS, inclusive para a conservação de seu patrimônio. A partir dessa diretriz, os estados têm autonomia para definir a sua taxa.

Ao se analisar o nível racional - burocrático, na legislação estadual que institui a unidade gestora, apenas os estados do Acre, Alagoas, Amazonas, Espírito Santo, Goiás, Mato Grosso, Paraíba, Rio Grande do Norte e Santa Catarina evidenciam a cobrança de taxa administrativa para financiar a unidade gestora de RPPS. O estado do Acre ultrapassa o limite estabelecido em lei, cobrando 3\%. Dirigentes do Rio Grande do Sul, São Paulo e Tocantins, por meio do questionário, também afirmam cobrar taxa administrativa. Amazonas, São Paulo e Tocantins, afirmam que essa taxa é o suficiente para organizar e colocar em funcionamento a unidade gestora. Contudo o dirigente do Amazonas destaca que na hipótese dos recursos de Amazonprev se tornarem insuficientes, está definida em lei (art.8o da LC 30/2001) a responsabilidade de a Secretaria de Fazenda cobrir, temporariamente, eventual insuficiência financeira necessária ao custeio administrativo da Fundação.

Com relação aos recursos humanos necessários, as legislações que fazem referência ao assunto são as do: Acre, Alagoas, Amazonas, Bahia, Espírito Santo, Goiás, Mato Grosso, Mato Grosso do Sul, Pará, Paraíba, Pernambuco, Rio Grande do Norte, Santa Catarina e Sergipe.

O dirigente do Amazonas relata que em relação a estrutura de recursos humanos houve a formalização da cessão de servidores que atuavam na Secretaria de Administração. Mato Grosso do Sul, também teve seu quadro de pessoal formado por cedência de servidores. E São Paulo pela absorção de mão de obra da autarquia pré-existente e criação de quadro especial permanente e comissionado, tudo isso feito por meio de consultoria técnica contratada.

Com relação aos recursos materiais, o representante do Mato Grosso do Sul relata que vieram de doações. Já o estado do Amazonas afirma que diante das dificuldades da transição para um novo modelo de previdência, o estado do Amazonas garantiu a transferência de imóveis (inclusive para servir como sede da UG), móveis e títulos de Compensações de Variações Salariais (provenientes de contratos firmados com a união) nos termos dos arts. 47 e 48 da LC 30/200, além de aporte de recursos do Tesouro Estadual que permitiu a instalação de uma estrutura mínima para início das operações desta UG. Além do aporte do Tesouro Estadual, a celebração de convênios com o Ministério da Previdência Social para cessão de equipamentos de informática foi 
fundamental para impulsionar o início das operações da UG naquele estado.

O dirigente do Rio Grande do Sul, pelo questionário, afirma que apesar de ter atribuído ao IPERGS a gestão previdenciária, mantém até hoje a mesma estrutura defasada e ultrapassada e afirma que ao deixar de promover as alterações necessárias para que o gestor faça frente às novas atribuições, a unidade gestora deixa de cumprir o seu papel.

O dirigente do Amazonas quando questionado sobre como ocorreu a distribuição dos recursos para a implementação da unidade gestora, disse que os recursos inicialmente transferidos pelo Estado para implementação da Unidade Gestora foram distribuídos em um plano com base em planejamento estratégico implantado pela Administração da época, frente às demandas necessárias para implantação de uma Unidade Gestora de Previdência. Assim como o estado do Rio Grande do Sul que também teve aporte de recursos financeiros necessários pelo ente federativo, via secretaria da fazenda.

No que se refere ao imperativo consensual, não foram constatados conflitos entre os atores implementadores referentes aos recursos.

\section{SUPERVISÃO PARA O PROCESSO DE IMPLEMENTAÇÃO DA UNIDADE GESTORA}

A legislação federal não deixa claro como deverá ocorrer o processo de supervisão da existência ou não da unidade gestora em cada ente federativo, abordando apenas a obrigação de disponibilização de dados ao Auditor, o que tem mais relação com desenvolvimento correto das atividades executadas pela gestão de RPPS do que com a formação da instituição. Contudo, os questionários do Amazonas, Minas Gerais e Tocantins apontam o Certificado de Regularidade Previdenciária CRP como principal instrumento de supervisão, pois é necessária a existência da unidade gestora para emissão do certificado.

Ao se analisar o nível de decisões individuais para a definição dos mecanismos de supervisão, no que se refere à legislação que implementa a unidade gestora em cada estado, apenas a do Espírito Santo, Pará, Paraíba, Rio de Janeiro, Rio Grande do Norte não definem uma forma de supervisão para a unidade gestora. Os demais estados falam sobre supervisão de uma forma interna, ou seja, sobre os recursos financeiros e as contas da unidade gestora e não sobre a supervisão da existência ou não dessa unidade gestora, o que é confirmado nos questionários. Assim, o CRP continua como instrumento principal para verificação de que existe ou não unidade gestora no nível racional-burocrático.

Além disso, nas atas das reuniões do Conaprev fica nítida a importância do CRP para o fortalecimento da implementação da unidade gestora. 
[...] o Representante do Estado do Rio de Janeiro [...] lamentou que o maior obstáculo no Rio de Janeiro para a concessão do Certificado de Regularidade Previdenciária, seja justamente a Unidade Gestora. Sugeriu [...] que o Supremo fizesse um trabalho mais amplo de divulgação e esclarecimento à respeito das Emendas constitucionais $\mathrm{n}^{\mathrm{o}} \mathrm{s} 20$ e 41 . (ATA DA $17^{\mathrm{a}}$ REUNIÃO DO CONAPREV, 2005, p. 4)

[...] o fundo previdenciário do Rio de Janeiro foi criado em 1999. Ele afirma que no seu Estado existem cinco regimes próprios e que ainda não foi conseguida a implantação da gestão única. Ele acrescenta que o projeto de Lei que unifica o processo de previdência aguarda aprovação da Assembléia Legislativa. Ele enfatiza a importância do CRP (ATA DA $22^{\underline{a}}$ REUNIÃO DO CONAPREV, 2007, p. 11)

[...]o Acre está sem CRP. Ele afirma que o CRP com a sua força coercitiva é responsável por grande parte do avanço na questão previdenciária. Ele conta que está aguardando a vinda dos Poderes para a efetivação da unidade gestora única. (ATA DA $22^{\underline{a}}$ REUNIÃO DO CONAPREV, 2007, p. 6)

Na $23^{\underline{a}}$ reunião do Conaprev em 2007 foi questionada a possibilidade de prorrogação da data para entrar em vigor o critério da unidade gestora única para a obtenção do CRP, que estava marcada para 01/01/2008. Segundo levantamento realizado, dos vinte e sete estados da federação, treze estavam regulares, nove irregulares e cinco em análise (ATA DA 23 $3^{\underline{a}}$ REUNIÃO DO CONAPREV, 2007, p. 6).

Os estados de Minas Gerais, Pará, Rio Grande do Norte, Acre e DF foram a favor à prorrogação do prazo, apontando como justificativa o desgaste político que poderia advir do não adiamento, o desgaste sobre o poder Executivo, a punição da população do estado, além de serem favoráveis ao diálogo.

Já os estados de Santa Catarina, São Paulo, Rio de Janeiro, Ceará, Espírito Santo, Sergipe e Curitiba não foram a favor da prorrogação e suas justificativas foram: o descrédito à gestão única, colocando em risco o futuro dos regimes próprios, pois se trata de um mandato constitucional; a perda de credibilidade perante o poder Judiciário e o Ministério Público; e perda de controle, por não cumprir uma questão legal. Além disso, não acreditavam que isso resolveria o problema principal.

Segundo os dirigentes do Amazonas, Ceará, Mato Grosso do Sul, Rio Grande do Sul, São Paulo e Tocantins, em questionário, afirmam possuir o CRP. Contudo, ao tomar por base os demais resultados encontrados nesta pesquisa, estes estados não possuem unidade gestora 
efetivas, fazendo com que surja um questionamento sobre a eficácia do CRP como supervisão da existência da unidade gestora nos estados.

O Quadro 2, apresenta as principais características encontradas em cada categoria e subcategoria.

\section{CONCLUSÕES}

Este artigo analisou o processo de implementação da unidade gestora de RPPS nos estados brasileiros, pela ótica de seus elementos fundamentais: a elaboração, os recursos e a supervisão. Cada um desses elementos é regido pelos imperativos legal, racional-burocrático e consensual.

Dessa forma, ao verificar a fase de elaboração da unidade gestora no âmbito do imperativo legal percebe-se que, a EC 41/2003, que torna a unidade gestora uma obrigação, não serviu como um ponto de referência para sua implementação, sendo necessários outros instrumentos como orientações normativas, portarias e até mesmo outras leis para que o sentido de unidade gestora pudesse ser melhor compreendido pelos implementadores.

É fato que ocorreram diálogos entre os representantes de RPPS dos estados brasileiros e o Ministério da Previdência Social através do Conaprev, em que algumas questões puderam ser resolvidas e outras geraram conflito entre o que a legislação dizia e o que era esclarecido verbalmente aos estados pelos representantes do MPS. Pode-se considerar que, a divergência de informações é um elemento que dificulta a implementação da unidade gestora, já que a legislação poderia ser interpretada sob formas diferenciadas e não existia um consenso ente MPS e executores da implementação da unidade gestora.

Assim, a unidade gestora foi definida com mais clareza após seis anos da publicação da EC 41/2003, com a ON 02/2009 e os estados demonstram saber por que devem implementar a unidade gestora, contudo, a legislação federal e as conversas com o MPS mostraram-se insuficientes por não evidenciar como deve ser executada a implementação da unidade gestora.

Quando analisadas as decisões no nível dos implementadores, pelo imperativo racional-burocrático, foi possível perceber que ao levar em consideração o que é expresso nos instrumentos legais federais, a unidade gestora poderia exercer administração de forma direta ou indireta. Dessa forma, parece não existir problema em denominar de unidade gestora o que existe nos estados que não possuem todas as funções de um RPPS centralizado na unidade gestora, criando um ponto de questionamento e levando à diversos níveis de entendimento por parte dos implementadores sobre o que seria a unificação. O Estado de São Paulo, por exemplo, em suas legislação apresenta essa unificação, mais na fala no Conaprev deixa a entender que na prática não é assim. Ou seja, as decisões em casos isolados expressas na forma de lei são diversas e quando levadas para a prática podem contrariar a própria legislação do estado, e isso é resultado da amplitude da legislação federal. 
Além disso, fica claro que a implementação da unidade gestora é um processo que está acontecendo de maneira gradual nos estados, devido principalmente aos conflitos de interesse, onde a grande dificuldade apontada pelos estados são os conflitos com os Poderes, quando se analisa o imperativo consensual. E também é um processo que permite uma evolução e um regresso, exemplo Minas Gerais.

Assim, os conflitos de interesse entre os Poderes também são importantes para a não existência da unidade gestora efetivas. Porém não é o único, o próprio Ministério da Previdência Social com delegação de funções aos Poderes, acaba por enfraquecer a credibilidade da unidade gestora. Os militares também são um grupo de pressão, por possuírem uma atividade diferenciada e são acostumados com as benesses do Estado.

Um projeto com o consenso de todos os envolvidos, poderia servir de base para a implementação, mesmo que adequações pudessem ser necessárias para realidade de cada ente. Assim, soluções são apresentadas pelos dirigentes de RPPS nas reuniões do Conaprev para a resolução dos conflitos como, participação de todos os envolvidos no processo de implementação através de comissões, além de fortalecimento da legislação e a supervisão dos processos.

Com relação aos recursos, o principal para a construção e manutenção da unidade gestora é a taxa de administração, dentro do imperativo legal, em que cada estado tem autonomia para fixar seu valor, desde que fiquem no limite de $2 \%$ do valor total das remunerações, proventos e pensões dos segurados vinculados ao RPPS, relativos ao exercício financeiro anterior. Contudo, pode-se concluir que a definição dos recursos foi feita de maneira tardia, após três anos da EC41/2003.

Ademais, outros recursos foram necessários para colocar a unidade gestora em funcionamento em cada estado, mesmo que não possuindo todas as características de uma unidade gestora, como recursos humanos e materiais que não estavam previstos na lei, mas que tiveram que ser providenciados, seja com a ajuda do governo do estado, doações ou concessões.

Outro aspecto que chama atenção é que a legislação federal não específica como deverá ocorrer a supervisão para a existência ou não da unidade gestora. Ao se observar as atas das reuniões do Conaprev e os questionários fica evidente que um importante mecanismo de supervisão é o CRP. Contudo ao confrontar com os demais resultados dessa pesquisa é perceptível que estados como Amazonas, Mato Grosso do Sul, Rio Grande do Sul e São Paulo, que na prática não possuem unidade gestora com todas as suas características, afirmam ter CRP, mostrando a fragilidade desse instrumento para supervisão da unidade gestora. 


\section{Revista de Gestão Pública}

PRÁTICAS E DESAFIOS

ISSN: 2177-1243

QUADRO 2: Resumo das categorias do processo de implementação da Unidade Gestora de RPPS.

\begin{tabular}{|c|c|c|}
\hline Categorias & Subcategorias & Resultados \\
\hline \multirow{3}{*}{ Elaboração } & Imperativo Legal & $\begin{array}{l}\text { EC } 41 / 03 \text { não foi suficiente para definir e permitir a interpretação de como } \\
\text { implementar a unidade gestora. } \\
\text { Assim outros instrumentos foram criados como a Lei } 10.887 / 04 \text {, a ON 03/04, } \\
\text { Portaria 402/08, ON 02/09 } \\
\text { Os instrumentos legais existentes não serviram como ponto de referência para o } \\
\text { processo de implementação e mesmo com tentativas de diálogo entre Ministério } \\
\text { da Previdência e representantes de RPPS dos estados, através do Conarev, } \\
\text { dúvidas permaneciam. }\end{array}$ \\
\hline & $\begin{array}{l}\text { Imperativo } \\
\text { Racional - } \\
\text { Burocrático }\end{array}$ & $\begin{array}{l}\text { Cada estado tem autonomia para criar a lei que institui a unidade gestora e } \\
\text { definir seu funcionamento, respeitando o que a lei federal determinar. } \\
\text { As decisões tomadas por cada estado tiveram as seguintes conseqüências: } \\
\text { - Estados que possuem legislação sobre RPPS antes da lei federal que institui a } \\
\text { UG: Amazonas, Espírito Santo, Pará, Paraíba, Paraná, Pernambuco e Rondônia. } \\
\text { - Estados que ajustaram suas legislações após a EC41/2003 e passaram a } \\
\text { denominar UG: Amazonas, Espírito Santo, Paraná. } \\
\text { - Estados que não denominam UG: Pará, Paraíba, Pernambuco, Rondônia, Amapá } \\
\text { e Sergipe. } \\
\text { - Estados que possuem todas as características de uma UG em sua legislação: } \\
\text { Sergipe, Espírito Santo, São Paulo, Goiás. } \\
\text { - Na prática o único estado que executa todas as atividades pertinentes ao RPPS } \\
\text { sendo um a UG, segundo essa pesquisa, é Tocantins. }\end{array}$ \\
\hline & $\begin{array}{l}\text { Imperativo } \\
\text { Consensual }\end{array}$ & $\begin{array}{l}\text { Falta de apoio dos Poderes na maioria dos estados; } \\
\text { Divergências nas instruções do MPS, enfraquecendo a UG; } \\
\text { Oposição dos Militares. }\end{array}$ \\
\hline
\end{tabular}




\section{Revista de Gestão Pública}

\begin{tabular}{|c|c|c|}
\hline \multirow{3}{*}{ Recursos } & Imperativo Legal & $\begin{array}{l}\text { A legislação que regulamenta a unidade gestora diz que a taxa de administração } \\
\text { deverá ser de até } 2 \% \text { do valor total das remunerações, proventos e pensões dos } \\
\text { segurados vinculados ao RPPS, relativos ao exercício financeiro anterior. }\end{array}$ \\
\hline & $\begin{array}{l}\text { Imperativo } \\
\text { Racional - } \\
\text { Burocrático }\end{array}$ & $\begin{array}{l}\text { Os estados que definiram taxa de administração na legislação foram: Acre, } \\
\text { Alagoas, Amazonas, Espírito Santo, Goiás, Mato Grosso, Paraíba, Rio Grande do } \\
\text { Norte e Santa Catarina. } \\
\text { Os estados que afirmaram possui taxa de administração por questionário foram: } \\
\text { Rio Grande do Sul, São Paulo e Tocantins. } \\
\text { Acre é o único estado que cobra uma taxa maior do que a prevista na legislação } \\
\text { federal. } \\
\text { Não foram encontrados evidencias sobre a taxa de administração para os demais } \\
\text { estados. } \\
\text { Recursos humanos, quando evidenciados, eram provenientes de concessões e } \\
\text { absorções. } \\
\text { Recursos matérias, quando evidenciados, eram provenientes de doações e } \\
\text { transferência. }\end{array}$ \\
\hline & $\begin{array}{l}\text { Imperativo } \\
\text { Consensual }\end{array}$ & $\begin{array}{l}\text { Não foram constatados conflitos entre os atores implementadores referentes aos } \\
\text { recursos, uma vez que esses atores estão preocupados com a elaboração da UG, } \\
\text { ou seja, compreender seu conceito e como colocá-lo em prática. }\end{array}$ \\
\hline \multirow{3}{*}{ Supervisão } & Imperativo Legal & Não definida em lei federal. \\
\hline & $\begin{array}{l}\text { Imperativo } \\
\text { Racional - } \\
\text { Burocrático }\end{array}$ & $\begin{array}{l}\text { Para os estados, o principal mecanismo seria o CRP. Contudo, não é eficaz na } \\
\text { prática. }\end{array}$ \\
\hline & $\begin{array}{l}\text { Imperativo } \\
\text { Consensual }\end{array}$ & Não foram constatados conflitos entre os atores implementadores. \\
\hline
\end{tabular}

Portanto, conclui-se que, a unidade gestora é um importante instrumento para diminuir o problema de desequilíbrio financeiro e atuarial do RPPS. Contudo, os estados brasileiros ainda encontram dificuldades para sua implementação, por ser um processo complexo e com conflitos de interesses, além da inexistência sobre prazos para organização do processo. Além disso, exige a formação de mecanismos de supervisão mais eficientes. 
Assim, como já apontado no referencial teórico deste artigo, a falta de clareza, definição de recursos e complexidade do processo são conflitos que não foram completamente resolvidos no contexto da unidade gestora única dificultando o processo de implementação, por não possuir consistência entre os imperativos legal, racional-burocrático e consensual.

\section{REFERÊNCIAS}

BRASIL. Emenda Constitucional no 41 , de 19 de dezembro de 2003. Modifica os arts. 37, 40, 42, 48, 96, 149 e 201 da Constituição Federal, revoga o inciso IX do $\S 3$ do art. 142 da Constituição Federal e dispositivos da Emenda Constitucional no 20, de 15 de dezembro de 1998, e dá outras providências. Diário Oficial [da] República Federativa do Brasil, Brasília, DF, 19 dez. 2003. Disponível em: http://www.planalto.gov.br/ccivil_03/ Constituicao/Emendas/Emc/emc41.htm. Acesso: 10/07/2015.

BRASIL. Ministério da Previdência Social. Anuário Estatístico da Previdência Social 2013. 2013. Disponível em < http:// www.previdencia.gov.br/wp-content/uploads/2015/o3/ AEPS-2013-v.-26.02.pdf > Acesso: 28 de fev. de 2015.

BRASIL. Ministério da Previdência Social/ Secretaria de Políticas de Previdência Social. Portaria 402, de 10 de dezembro de 2008. Diário Oficial [da] República Federativa do Brasil, Brasília, DF, 12 dez. 2008. Disponível em: http://www.previdencia.gov. br/wp-content/uploads/2014/12/PORTARIA-MPS-N\%C2\%BA402-de-2008-Atualiz.29dez2014.pdf. Acesso: 10/07/2015.

BRASIL. Ministério da Previdência Social/ Secretaria de Políticas de Previdência Social. Orientação Normativa 02, de 31 de março de 2009. Diário Oficial [da] República Federativa do Brasil, Brasília, DF, 02 abr 2009. Disponível em: http://www.previdencia. gov.br/wp-content/uploads/2014/o9/ORIENTA\%C3\%87\%C3\%83ONORMATIVA-SPS-02-de-31mar2009-atualizadaat $\% \mathrm{C}_{3} \%$ A9-11jul2014.pdf. Acesso: 10/07/2015.

BRASIL. Ministério da Previdência Social/ Secretaria de Políticas de Previdência Social. Orientação Normativa 03, de 12 de agosto de 2004. Diário Oficial [da] República Federativa do Brasil, Brasília, DF, 17 agosto 2004. Disponível em: http://www.previdencia.gov.br/arquivos/ office/3_081014-105056-362.pdf. Acesso: 10/07/2015.

BRASIL. Lei 10.887, de 18 de julho de 2004. Dispõe sobre a aplicação de disposições da Emenda Constitucional no 41, de 19 de dezembro de 2003, altera dispositivos das Leis nos 9.717, de 27 de novembro de 1998, 8.213, de 24 de julho de 1991, 
9.532, de 10 de dezembro de 1997, e dá outras providências. Diário Oficial [da] República Federativa do Brasil, Brasília, DF, 18 jul. 2004. Disponível em: http://www.planalto.gov.br/ ccivil 03/ ato2004-2006/2004/lei/lio.887.htm. Acesso: 10/07/2015.

BRYNARD, P.; DE CONING, C. Policy implementation. In: CLOETE, F.; WISSINK, H.; DE CONING, C. Improving public policy, from theory to Practice. Van Schaik: Pretoria. 2006.

Conaprev. São Luiz do Maranhão. Ata da décima segunda Reunião Ordinária de julho de 2004. Disponível em: http:// www.conaprev.org.br/institucional.php . 25/05/2015.

Conaprev. Brasília. Ata da décima terceira Reunião Ordinária de setembro de 2004. Disponível em: http:// www.conaprev.org.br/institucional.php. 25/05/2015.

Conaprev. Manaus. Ata da décima sétima Reunião Ordinária de novembro de 2004. Disponível em: http:// www.conaprev.org.br/institucional.php. 25/05/2015.

Conaprev. Alagoas. Ata da vigésima Reunião Ordinária de novembro de 2006. Disponível em: http://www. conaprev.org.br/institucional.php. 25/05/2015.

Conaprev. Paraíba. Ata da vigésima segunda Reunião Ordinária de maio de 2007. Disponível em: http:// www.conaprev.org.br/institucional.php. 25/05/2015.

Conaprev. Brasília. Ata da vigésima terceira Reunião Ordinária de dezembro de 2007. Disponível em: http:// www.conaprev.org.br/institucional.php. 25/05/2015.

Conaprev. Brasília. Ata da vigésima sexta Reunião Ordinária de setembro de 2008. Disponível em: http:// www.conaprev.org.br/institucional.php. 25/05/2015.

Conaprev. Salvador. Ata da vigésima sétima Reunião Ordinária de novembro de 2008. Disponível em: http:// www.conaprev.org.br/institucional.php. 25/05/2015.

Conaprev. Pernambuco. Ata da vigésima oitava Reunião Ordinária de abril de 2009. Disponível em: http:// www.conaprev.org.br/institucional.php. 25/05/2015.

Conaprev. São Paulo. Ata da trigésima Reunião Ordinária de outubro de 2009. Disponível em: http:// www.conaprev.org.br/institucional.php. 25/05/2015.

Conaprev. Brasília. Ata da trigésima segunda Reunião Ordinária de abril de 2010. Disponível em: http://www. 
conaprev.org.br/institucional.php. 25/05/2015.

CALAZANS, F. F. et al. Entidade gestora única nos Regimes Próprios de Previdência: em busca de um conceito. Revista do TCE-PE, v. 19, n. 19, p. 160-174, 2012.

CALAZANS, F. F. et al. Entidade gestora única nos Regimes Próprios de Previdência: em busca de um conceito. Revista do TCE-PE, v. 19, n. 19, p. 160-174, 2012.

CALAZANS, F. F. Participação e controle social: a experiência da gestão compartilhada nos regimes estaduais de previdência dos funcionários públicos Revista do TCEMG - abril/maio/junho, v. 31, n. 2 , ano 2013.

CALAZANS, F. F. et al. A importância da unidade gestora nos regimes próprios de Previdência Social: análise da situação dos estados e do Distrito Federal. Revista de Administração Pública, v. 47, n. 2, p. 275 a 304, 2013.

CALAZANS, F. F.; CAETANO, M. Abi-Rama. A política regulatória contemporânea dos regimes de previdência do funcionalismo público no Brasil: avanços, limitações e propostas. 2013.

CAVALCANTE JÚNIOR, H. M; ALMEIDA, P. C. Análise do Sistema de Previdência dos Servidores Públicos Estaduais do Estado do Ceará. Conhecer: Debate entre o Público e o Privado, v. 1, n. 3, 2012.

FREY, K. Políticas públicas: um debate conceitual e reflexões referentes à prática da análise de políticas públicas no Brasil. Planejamento e Políticas Públicas. 21(1), 211- 259. Brasília: IPEA. 2015.

JANN, W.; WEGRICH, K. Theories of the Policy Cycle. In: FISCHER, F.; MILLER, G. J.; SIDNEY, M. S. Handbook of Public Policy Analysis. New York: CRC Press, Cap. 4, 2007.

NOGUEIRA, N. G. Equilíbrio financeiro e atuarial do RPPS: de princípio constitucional a política pública de Estado. Coleção Previdência Social. Série Estudos, v.34. Brasília:MPAS, 2012.

REIN, M.; RABINOVITZ, F. F. La implementación: una perspectiva teórica. Entre la intención y la acción. In: VILLANUEVA, L. F. La implementación de las políticas. México, Porrúa, 1993.

SANTOS, H. As reformas da previdência no Brasil e o equilíbrio e atuarial dos Regimes Próprios de Previdência Social (RPPS), dos entes federados estaduais da Região 
Sudeste. Dissertação de mestrado FGV RJ. 2014.

SCHWARZER, H. Previdência Social: reflexões e desafios. Coleção Previdência Social, Série Estudos, v.3o. Brasília: MPAS, 2009.

SECCHI, L. Políticas públicas: conceitos, esquemas de análise, casos práticos. São Paulo: Cengage Learning, 2013.

VELTEN, S. R. Unidade gestora única do regime próprio de previdência: estudo de caso do governo do estado do espírito santo. Rede De Ensino Luiz Flávio Gomes. Trabalho de conclusão de curso de pós graduação apresentado à Universidade AnhangueraUniderp Rede de Ensino Luiz Flávio Gomes, 2013. 